Note

\title{
Good practice: Improving and assessing honors student learning with learning portfolios
}

John Zubizarreta

Columbia College, South Carolina, U.S.A.

Correspondence: jzubizarreta@columbiasc.edu

Received: 5 September 2018; Accepted: 26 November 2018; Published: 7 January 2019

Keywords: portfolio, reflection, assessment

Note to reader: honors keywords (see introductory article of this issue) in italics in the text

\section{Introduction}

The learning portfolio is a rich, convincing, and adaptable method of recording intellectual growth and involving students in a critically reflective, collaborative process that augments learning as a community endeavor and refines their educational experience. It is a concept that can be custom-tailored to suit many disciplinary, pedagogical, programmatic, and institutional needs. In honors, especially, the portfolio helps students achieve the goals of honors education to foster academic competence, creativity, critical thinking and writing, integrative learning, and metacognitive skills for deep and lasting learning. With today's technological advantages of digital media, learning portfolios created with e-portfolio platforms introduce new and exciting opportunities for honors programs to demonstrate and assess the value-added dimensions of honors courses and other experiences designed to challenge students and enhance their learning. This good practice is not related to a specific honors program or institution but is a more general description of a good practice based on experiences in many honors programs.

\section{Why this good practice?}

Portfolios - whether constructed as web-based e-portfolios, computer disks, multi-media productions, or paper binders - offer ambitious, motivated students a living, practical tool for representing and documenting their learning and real abilities, going far beyond the evidence showcased in a simple résumé or letter of recommendation for further educational endeavors or professional career aspirations. The documentation function of portfolios is useful for assessment of student learning and program effectiveness, but the core value of any sound portfolio project is an intentional, primary focus on learning. Such a focus leads to deliberate and systematic attention not only to skills development but to a student's self- 
reflective, metacognitive understanding and appraisal of what is learned, how it is learned, when it is learned best, and, more importantly, why learning is meaningful, practical, transferable, and durable as a life-long endeavor.

\section{Target group and target group size}

Students in an honors program or college benefit from beginning construction of a learning portfolio in their first year, perhaps in a first-year seminar as part of an honors curriculum. They update their reflections and selected evidence of outcomes regularly each year in the program with the help of a peer or faculty mentor who offers feedback on the scope, richness, relevance, and structure of the portfolio. In a senior honors capstone, students can finalize the portfolio's content, consult with peer and faculty mentors and the program director, and decide what further use to make of the portfolio. A senior honors capstone experience could be a major activity situated within the final semesters of an honors program. Examples of this type of capstones include an honors thesis, senior papers or projects, or arts performances or exhibitions.

\section{Educational design (structure)}

The intrinsic merit of learning portfolios is that they involve students in the power of reflection, the critically challenging process of thinking about their learning and making sense of the learning experience as a coherent, integrated, developmental process. Such thinking is the linking pin of life-long, active learning, the key to helping students discover and understand what, how, when, and why they learn.

With reflection at the heart of portfolio work, students design their portfolios to include critical analysis and selected evidence of their learning. Selection of portfolio items is driven by purpose and goals, making each portfolio unique and expressive of individual accomplishments and aspirations. One issue that often surfaces in portfolio development is when students mistakenly perceive that the portfolio is merely a repository for every scrap of work they accumulate over time. An important reminder here is that a sound portfolio consists of selected evidence, and the regular faculty or peer mentoring mentioned earlier is an essential component of the portfolio process that offers students the timely feedback needed to help with judicious selection of portfolio materials.

Often, both reflective narrative and documentation are keyed to honors programs' stated goals and competencies, helping students and program directors to assess students' progress as learners and members of the program. Because the portfolio is a process as well as a product that comprises multiple sources of reflective and documentary evidence, students become more self-directed and self-regulating learners, and faculty and directors have more complete, diverse information to use for assessment and evaluation.

The structure of a portfolio can vary greatly, depending on purpose and goals and whether it is created electronically, on paper, or in some other alternative media (as in the case of portfolio video productions). The e-portfolio offers the advantage of allowing organized, embedded links to selected supporting information such as scanned essays in drafts with improvements from feedback, performance on exams, homework assignments, lab reports, videos of class or conference presentations, photos, samples of creative work, research results, résumé, letters of support or evaluation, internship evaluations, learning journals of 
travel-study ventures or service endeavors, and more. The reflective component is at the center, helping to tie together the various other dimensions of the portfolio.

While critical reflection for deep learning should always be the main objective of portfolio development, technology is an asset that permits many ways to represent a student's growth in honors, and the e-portfolio is today's most popular medium. Many institutions use commercial platforms such as Blackboard, Canvas, Chalk\&Wire, Digication, LiveText, PebblePad, or others. Some construct their own home systems. Many e-portfolio projects use free providers such as WIX, Weebly, FolioSpaces, Mahara, WordPress, or other opensource systems. Judging from the popularity of e-portfolios throughout the United States, Canada, European nations, Australia, New Zealand, and others, e-portfolios are clearly more than a passing trend.

\section{Student assessment}

Learning portfolios have diverse applications. They can provide a device for demonstrating the value of experiential learning or assessing credit for prior learning. In business and teacher education, portfolios have been used commonly as effective tools for career preparation. Some portfolios are shared by students and faculty advisors for the purpose of academic and career advising. Portfolios are also useful for assessment of student learning and program effectiveness. Since the portfolio includes multiple carefully selected, authentic types of evidence of learning keyed to program or college goals and competencies, it is a convincing source for documenting students' achievements as well as a program's successes and areas for improvement. With intentional, careful mentoring, a student can collect vital information from different courses and experiences to showcase and assess accomplishments in honors.

\section{Experiences}

In my own honors program at Columbia College, students began creating paper portfolios in the first year and other advanced classes more than a decade ago, a modest start to engaging them in the power of reflective practice. More recently, students use free opensource web platforms to design e-portfolios that include reflective writing in an online forum, formal essays, work in draft stages with feedback, class and reading notes, videos, presentation slides, photos, essay exam responses, research projects, and other samples of their work.

The portfolio concept is introduced to new students during their specially designed, studentled, three-day orientation to the program, giving them an introduction to how reflective practice is an important dimension of honors education. We instill in them an appreciation for how "portfolio thinking" - that is, embracing how all their encounters inside and outside the classroom are moments for critical reflection, for making connections, and for applying and extending their learning - is one of the ways in which their honors experiences in courses and out-of-class ventures will be unique, challenging, and fulfilling. When they begin to develop actual portfolios in a first-year honors course and later add or exchange selected evidence of their learning and achievement of honors program goals and outcomes, they assemble a record of their intellectual and personal growth as learners and as members of the program. Their portfolios have been used in professional conference sessions to 
demonstrate the potential of learning portfolios in enhancing and documenting such student learning.

In most cases, their first portfolio project occurs when they land in my first-year composition and literature honors course, where the learning portfolio typically counts for about onefourth of their final grade, high stakes enough for a serious effort but low stakes enough not to damage overall success in the course. Later, in other honors courses, students may encounter a "Portfolio Assignment" or "PA" designed to offer a viable sample of work that demonstrates competency in a particular honors program goal or outcome.

Many programs today use such portfolios to document the value-added benefits of honors and the effectiveness of their efforts to deepen students' learning. Such programs must decide whether portfolios will be used in all or some honors courses, whether they will only be part of individual course assessments as chosen by instructors, whether they will "count" toward a student's requirements for finishing honors, or whether they will factor in overall program evaluation for institutional review. All of these scenarios can be found today in the honors landscape, but in all cases, thoughtful and consistent mentoring is essential to ensure that students learn the important skills and habits of meaningful critical reflection and selfassessment. Introduction in an orientation, follow-up in different types and levels of courses, regular occasions to consult with the director, perhaps at Honors Student Association monthly meetings, and interaction with trained peers throughout progress in an honors program are viable ways of providing students with the mentoring that will help them produce sound portfolios.

Do honors students understand and appreciate the value of portfolio work? Here are some testimonials from students ranging from first-year to senior-level learners:

- This way of reflecting on my learning and showing real evidence of what I have accomplished has contributed to my personal life in that it has made me a better learner in all academic and other challenges I have faced.

- My learning ability reached its highest potential in this portfolio, and I feel like a brand new student. Some may call this "enlightenment" a point in my own journey in life, and the portfolio helped me understand myself and my learning on this journey. It was more than just a grade.

- Having to explore and improve my thinking through the components of a portfolio taught me how to adapt to different ways of learning, and it affected me tremendously overall.

- I can see my growth as a learner through the process of all my honors (and other) courses. To me, the portfolio was another way to think about what I got out of my education because I could transform my thinking into writing in a selective and intellectual way.

- I have found that my ability to think critically has been challenged by the portfolio. I often find that my level of thinking does not exceed the second or third levels of Bloom's taxonomy, but I was able to spend significantly more time evaluating and creating material regarding my learning through my own opinions and thoughts rather than relying so heavily on empirical source work. Eventually, I was able to "get it" when it comes to the power of reflection in learning. 
- While I have learned a lot about myself in this course through our portfolio, I have also learned about other classes and my personal life. I have used the creation of a portfolio in our class to think more critically in my different classes.

- The portfolio provided me with a freedom to choose how I wanted to show and discuss my learning and how my thinking process occurred. I could control how I approached the assignment. Before this class, other professors would give prompts to assignments or a selection of ideas I could choose from and focus on for the assignment. When I realized the freedom I would be given to create my portfolio and that I would not be given required prompts, it was a daunting concept at first for me personally. Also, I felt lost and unsure how I would tackle the parts of the portfolio. However, I slowly got used to the idea of having free reign in the design, and I began to enjoy organizing the portfolio to reveal my strengths and weaknesses in my learning.

- While the traditional school system of sitting in a hard desk, taking tests, and being an obedient silent mouse is what I knew before the honors program, this class and its emphasis on reflection and a learning portfolio altered my perspective on learning. The portfolio showed me that there are other ways to encourage learning without hanging a grade over my head. When a comfortable environment is created, reflection can be fun, useful, and can elicit greater learning.

- This semester, I feel I've grown as a reader, thinker, and learner because I've taken active control of my learning and directed the content to where I wanted to go in my portfolio. I loved that I had the freedom to explore my own wanderings and that I always had some place to share them. Being able to take control of my learning in this way gave me a feeling of confidence and excitement.

- I think I grew as a critical thinker through portfolio focus on reflection. I feel very deeply that I learned something invaluable, and that a veil was lifted from my eyes, which now allows me to see all my learning in an entirely new light and with much more depth than I was previously able to view it. I also had a lot of fun because of the portfolio's versatility, as I felt that I had the freedom to grow and explore on my own, and within the areas of my interest, while still being exposed to areas outside of my interests.

\section{Time requirement for teachers}

Honors instructors and directors interested in exploring the power of learning portfolios have many resources available on the web to help implement portfolios in courses and programs. Students tend to enjoy using web programs to design e-portfolios as they use their imagination to represent their learning in creative ways with the advantages of digital technology. I have found that my time investment has been fairly minimal because students take charge of playing with the technology and owning their own work with the portfolio and finding their individual voices as they collect, select, and reflect while constructing their portfolios. My investment consists of helping students to identify purpose, goals, and appropriate evidence; mentoring them in the challenge of writing meaningful reflective narratives; providing feedback on structure and content; and suggesting ways in which the portfolio can serve practical aims for further education or career pursuits. I start these conversations in honors orientation and follow up in a first-year course that either I or an honors colleague teach. I touch base with students periodically during monthly honors student group meetings. Some programs have a faculty "honors council" or "committee" 
that can be tapped to help mentor students and provide written or oral feedback at the end of each academic year so that students know if they are on track or need to improve their portfolios for final assessment. Some programs use trained peer consultants to help with such mentoring, relieving some of the teacher's time.

One anxiety that teachers express is how much time is needed to assess and evaluate portfolios, especially if they are collected and used for programmatic review. I suggest that a revolving number of instructors in varied courses throughout a student's career identify one honors assignment or activity as a "Portfolio Assignment." The "PA" product is flagged as an item that can be included in a comprehensive portfolio. The selected work can be tied to program goals and competencies, and, with proper mentoring through academic advisement or peer consultation, the student can learn to distinguish what product best reveals achievement toward a program's stated outcomes. All such work will already have received feedback and will already have been evaluated in courses, and so the embedded assessment makes any final review of the portfolio very manageable.

Remember, however, that learning portfolios may be used only as partial fulfillment of individual course requirements ("course portfolios"), but if they are used as comprehensive demonstrations of student achievement of program competencies, then a review committee may agree to accept the embedded assessment of varied course artifacts in the portfolio and focus, instead, for example, on the quality of a final reflection and overall design. Depending on the size of the program, perhaps the "honors council" or a sub-committee of the group can constitute the review team. Conducting such a review early in the senior year conveniently, perhaps, within an honors capstone seminar or advisement opportunity allows for formative feedback and any improvements needed, and the portfolio can be part of the capstone grade, a requirement to earn honors graduation status, a showcased achievement in an honors scholars' celebration event, or a combination of such alternatives. Various possibilities exist for how portfolios are used and evaluated in courses, in final student learning assessment, or in overall program review, or whether they are graded at all but rather encouraged and supported for personal development.

\section{Tips for teachers}

Many books, articles, and web resources offer tips for tapping the benefits of learning portfolios, but one of the most important is to start slow and small. Do not jump headlong into a portfolio project, especially if it is electronic, expecting students and faculty to embrace the concept and understand the complexities of reflective practice, the skill of judicious selection of artifacts, the art of clear and compelling writing, the mechanical challenges of technology, and other issues. A modest portfolio assignment, integrated into the design and assessment of a course so that it is not simply another added requirement, is a good start. When more courses use portfolio strategies, then a program portfolio project can be the next step.

\section{Tips for students}

When students are skeptical or nervous about the value of portfolios, when they do not readily see how and why a learning portfolio is a vital and authentic representation of their honors education, when they question how a portfolio provides them with a practical showcase of their skills and accomplishments for further studies or career development, 
then they can be referred to the internet to find innumerable examples of actual student portfolios that will show them how portfolios help prepare them for the next stages in their lives. An honors program web site can include a section devoted to the value of portfolios, with links not only to resources and templates but also to exemplary models developed by honors students with accompanying testimonials about the intellectual and practical worth of portfolios during and after participation in an honors program. Learning portfolios, especially in digital form, have evolved to be much more than a passing trend in honors and in higher education generally. Encouraging students to browse the wealth of information and samples on the web is an effective wake-up call.

\section{Transfer to other programs}

Learning portfolios today, particularly with the surge of institutional e-portfolio projects, are used in countless ways and in countless colleges and universities around the world. In honors, the implementation of portfolio strategies is growing as honors programs are increasingly pressed to demonstrate the value-added dimension of honors education. Because honors has a specific mission, working with a special population of students and faculty toward intentional pedagogical goals and outcomes, it is advantageously poised to be innovative and creative in using portfolios successfully to enhance student learning and design an effective programmatic assessment method. Once tested and perfected in honors, the portfolio model can more easily transfer to other programs, strengthening teaching and learning throughout an institution.

\section{References, additional information and relation with Circle of Talent Development}

\section{$\underline{\text { References }}$}

Cambridge, D. (2010). E-portfolios for lifelong learning and assessment. San Francisco: Jossey-Bass.

Light, T. P., Chen, H. L., \& Ittleson, J. C. (2011). Documenting learning with portfolios: A guide for college instructors. San Francisco: Jossey-Bass.

Zubizarreta, J. (2009). The learning portfolio: Reflective practice for improving student learning. $2^{\text {nd }}$ ed. San Francisco: Jossey-Bass. $1^{\text {st }}$ ed. Bolton: Anker, 2004.

Zubizarreta, J., \& Corley, C. (2012). The power and utility of reflective learning portfolios in honors. Journal of the National Collegiate Honors Council 13(1), 63-76.

\section{Additional information}

Europortfolio: http://www.eportfolio.eu/

IDEA Paper \#44, https://www.ideaedu.org/Research/IDEA-Paper-Series

Inter/National Coalition for Electronic Portfolio Research: http://incepr.org/ 
Honors e-Portfolio examples:

http://www.mnsu.edu/honors/portfolios.html

https://www.uh.edu/honors/Programs-Minors/co-curricular-programs/eportfolio/what-iseportfolio/

https://www.odu.edu/honors/academics/eportfolios

https://honors.wayne.edu/eportfolio

https://macaulay.cuny.edu/eportfolios/

https://www.pace.edu/honors-college/pleasantville-students/opportunities/e-portfolio

\section{$\underline{\text { Relation with Circle of Talent Development }}$}

In the introductory article of this issue of JEHC, the 'Circle of Talent Development' has been described. Based on interviews with forty honors students and literature about honors programs, it reflects relevant activities of students regarding the development of their talents in an honors program. The author of this note has been asked to score the good practice in relation to the activities in the Circle of Talent Development. The meaning of the scores is: $+=$ somewhat important; $++=$ moderately important; $+++=$ very important; $-=$ not applicable or irrelevant. The scores are intended to illustrate the strengths of a good practice for the reader. 
Figure 1: Circle of Talent Development in relation with the good practice 'Improving and Assessing Honors Student Learning with Learning Portfolios' with the teacher's scores

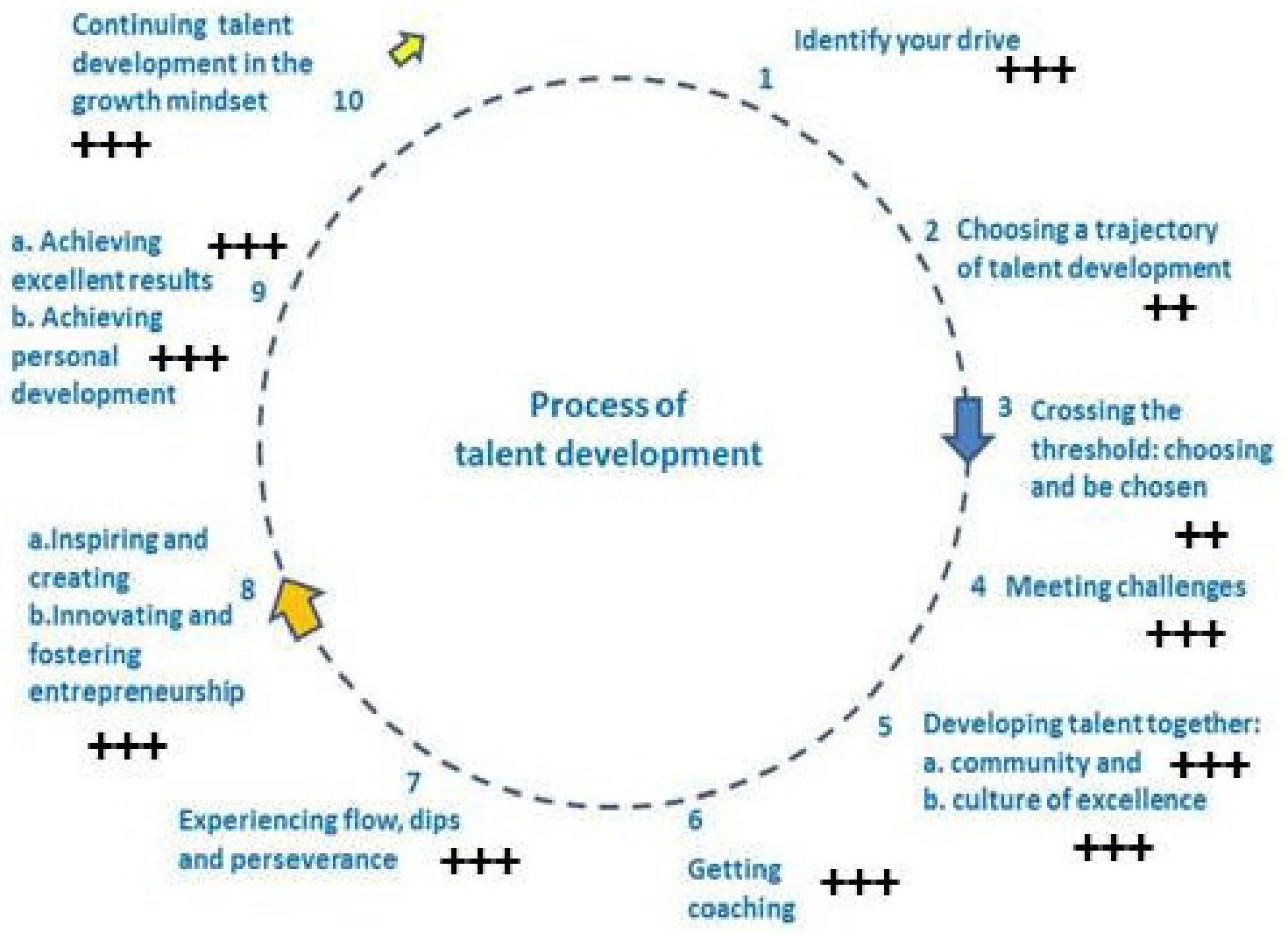

Question to the teacher: What makes this good practice attractive for other teachers? The teacher of this practice argues: 'As a teacher, I am always inspired by strategies and methodologies that focus on deepening and extending student learning through innovative practices inside and outside the classroom, especially when they involve helping students develop the challenging skills and habits of meaningful critical reflection so that they learn and master not only content information but also how to learn, how to connect and apply learning, and how to value learning as a lifelong endeavor. I am attracted to active learning approaches that engage students in more than received knowledge, competencies, outcomes, or grades. I gravitate toward teaching that, of course, helps students gain content expertise but also helps students make connections among different disciplinary ways of thinking, helps them explore divergent ideas, helps nurture their creativity, invites them to take risks, and reinforces their excitement for learning.' 